\title{
Chronic Lymphocytic Leukemia with Dermatomyositis: A Therapeutic Challenge
}

\author{
Dermatomyozitle Birlikte Kronik Lenfositik Lösemi: Bir Tedavi Mücadelesi
}

(D) Sudhir Kumar1, (D) Ajay Gogia1, (D) Ritu Gupta2 , (D) Soumya Mallick3

${ }^{1}$ AIIMS, Department of Medical Oncology, New Delhi, India

2AIIMS, Department of Laboratory Oncology, New Delhi, India

${ }^{3}$ AIIMS, Department of Pathology, New Delhi, India

\section{To the Editor,}

Chronic lymphocytic leukemia (CLL) is an indolent B-cell malignancy that is often complicated by autoimmune abnormalities like autoimmune hemolytic anemia and immune thrombocytopenia. Non-hematological autoimmunity occurs in 1\%-2\% of patients with CLL [1]. Dermatomyositis (DM) is an immune-mediated, inflammatory muscle disease that is reported to be associated with CLL and causes significant clinical dilemmas owing to its rarity. We report a case of CLL diagnosed concurrently with DM, treated with chemoimmunotherapy.

A 60-year-old man presented with a progressive skin rash over the base of the neck, knuckles of both hands, and trunk along with symptoms suggestive of proximal muscle weakness predominantly involving the lower limbs for 4 months. He had been bedridden for the preceding 2 months. On examination, he had erythematous, irregularly shaped plaques with crusting over the neck, upper chest (shawl sign) (Figures 1a and 1b), bilateral knuckles, and periumbilical area without any mucosal lesions. Central nervous system (CNS) examination showed bilaterally symmetrical proximal muscle weakness (grade 3/5), predominantly involving the lower limbs. The rest of the CNS and other systemic examinations were unremarkable. He had hemoglobin of $11 \mathrm{~g} / \mathrm{dL}$ and leukocytosis with an absolute lymphocyte count of $13224 / \mathrm{mm}^{3}$. Peripheral blood smear examination and flow cytometry were compatible with the diagnosis of CLL. The fluorescent in situ hybridization panel for CLL showed $13 q$ deletion. His creatinine kinase level was elevated at $2092 \mathrm{U} / \mathrm{L}$ (reference range: $10-225 \mathrm{U} / \mathrm{L}$ ), as was serum lactate dehydrogenase (557 U/L; reference range: $200-420 \mathrm{U} / \mathrm{L}$ ). Autoimmune panel, nerve conduction, and electromyographic studies were negative. Skin biopsy showed focal vacuolar interphase colloid bodies, papillary dermal edema, and dilated capillaries in the upper dermis with elastotic degeneration suggestive of DM (Figures 1c and 1d). The diagnosis of CLL (clinical Rai stage 0) with DM was made. He was started on prednisolone at $1 \mathrm{mg} / \mathrm{kg}$ and methotrexate at $15 \mathrm{mg} /$ weekly by a dermatologist; however, the rashes were gradually progressive. Due to his uncontrolled rashes after 2 months of steroid and methotrexate treatment and marked recent-onset fatigue, he was put on CLL therapy with a BR regimen (bendamustine at $90 \mathrm{mg} / \mathrm{m}^{2}$ and rituximab at $375 \mathrm{mg} / \mathrm{m}^{2} \mathrm{q} 28$ days). He then recovered from the rashes, weakness, and fatigue. He attained complete hematological and clinical remission after six cycles of $\mathrm{BR}$ and remains in follow-up and disease-free for the last 18 months.

Among 15 reported cases of CLL with inflammatory myositis in the last two decades, only six were associated with DM [2]. It is not known whether this association is coincidental or causal or merely due to patient selection bias. DM is usually diagnosed concurrently with (5 out of 6 reported cases) or after (1 out of 6 ) a diagnosis of CLL and it follows a parallel course, suggesting a pathogenic link between the two entities [2]. Tumor antigens triggering the autoimmune process either by mimicking endothelial antigens or via bystander stimulation and imbalance of T-cell subsets in CLL are the most reported hypotheses $[3,4]$. In general, the treatment of autoimmune complications in CLL has been the same as when the disease occurs spontaneously, but the question of whether and how to treat CLL itself persists. No treatment plan for 5 out of 6

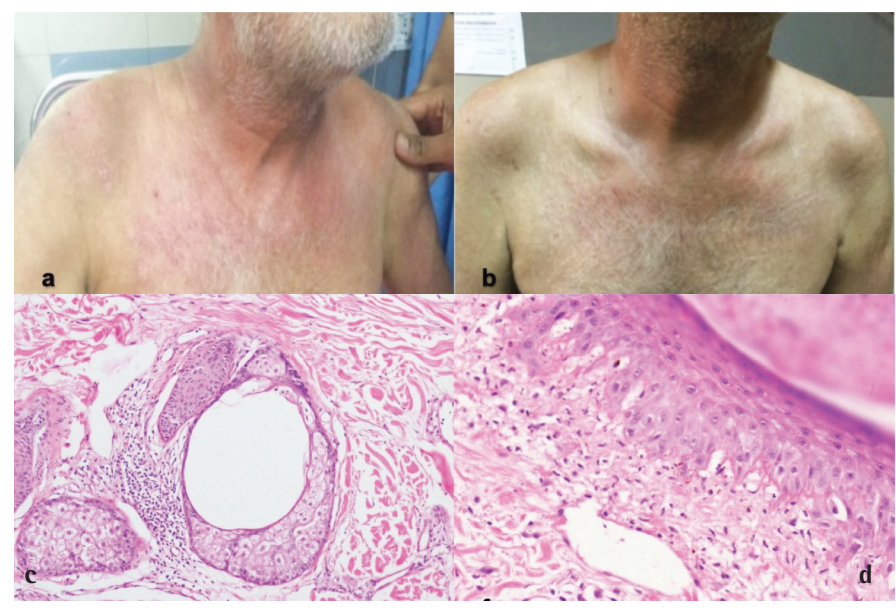

Figure 1. a) Erythematous, irregular, and crusting plaque-like skin rash (shawl sign) before treatment. b) Resolved skin rash after therapy. $\mathbf{c}$, d) Skin biopsy showing focal vacuolar interphase colloid bodies, papillary dermal edema, and dilated capillaries in the upper dermis with elastotic degeneration. 
cases of CLL with DM were reported, and one patient received methotrexate with cyclophosphamide. The skin rash in DM does not mean malignant skin involvement; therefore, DM treatment should be initiated separately, as in our case. However, DM with associated malignancy responds poorly compared to idiopathic cases [5]. Long-term outcomes of CLL with DM are unknown, and so are data regarding the use of chemoimmunotherapy in such patients, although rituximab has shown efficacy in DM [6]. It is prudent for the overworked clinician to not overlook neurological or musculoskeletal symptoms in CLL patients, and a keen search for hematological malignancy is justified in known cases of inflammatory myopathies.

Keywords: CLL, Cutaneous involvement, Rash

Anahtar Sözcükler: KLL, Deri tutulumu, Döküntü

Informed Consent: Informed consent has been obtained before writing this manuscript.

\section{Authorship Contributions}

Concept: S.K., A.G.; Design: S.K., A.G.; Data Collection or Processing: R.G., S.M., A.G.; Writing: S.K., A.G., R.G., S.M.
Ethics Committee Approval: This study has followed ethical standards.

Financial Disclosure: No funding was received for this study.

\section{References}

1. Hamblin TJ. Non-hemic autoimmunity in CLL. Leuk Res 2009;33:366-367.

2. Stübgen JP. Inflammatory myopathies and lymphoma. J Neurol Sci 2016;369:377-389.

3. Kay NE. Abnormal T-cell subpopulation function in CLL: excessive suppressor ( $\mathrm{T}$ gamma) and deficient helper ( $\mathrm{T} \mathrm{mu}$ ) activity with respect to B-cell proliferation. Blood 1981;57:418-420.

4. Gunawardena $H$, Betteridge ZE, McHugh NJ. Myositis-specific autoantibodies: their clinical and pathogenic significance in disease expression. Rheumatology (Oxford) 2009;48:607-612.

5. Marie I, Guillevin L, Menard JF, Hatron PY, Cherin P, Amoura Z, Cacoub P, Bachelez H, Buzyn A, Le Roux G, Ziza JM, Brice P, Munck JN, SarrotReynauld F, Piette JC, Larroche C. Hematological malignancy associated with polymyositis and dermatomyositis. Autoimmun Rev 2012;11:615-620.

6. Levine TD. Rituximab in the treatment of dermatomyositis: an open-label pilot study. Arthritis Rheum 2005;52:601-607.

- Copyright 2020 by Turkish Society of Hematology

Turkish Journal of Hematology, Published by Galenos Publishing House

\title{
IRF4-Rearranged Large B-Cell Lymphoma on Waldeyer's Ring: A Case Report
}

\author{
Waldeyer Halkasında IRF4 Yeniden Düzenlenmesi Büyük B-hücreli Lenfoma Olgusu
}

\author{
(D) Deram Büyüktaş${ }^{1}$, (D) Serdar Örnek², (D) Fatma Tokat ${ }^{3}$, (D) Tülay Tecimer ${ }^{4}$, (D) Burhan Ferhanoğlu1 \\ ${ }^{1}$ Koç University Faculty of Medicine, Department of Hematology, Istanbul, Turkey \\ ${ }^{2}$ American Hospital, Clinic of Hematology, Istanbul, Turkey \\ ${ }^{3}$ Acıbadem University Faculty of Medicine, Department of Pathology, Istanbul, Turkey \\ ${ }^{4}$ Acıbadem Health Group, Pathology Laboratory, Istanbul, Turkey
}

\section{To the Editor,}

Large B-cell lymphoma ( $\mathrm{LBCL}$ ) with IRF4 rearrangement is a newly recognized and rare entity. $\mathrm{LBCL}$ is characterized by coexpression of MUM1 and BCL6. It has been associated with young age and a favorable outcome. Most patients present with predominantly Waldeyer's ring or neck or head lymph node involvement $[1,2,3]$. Here, we present a case of LBCL with IRF4 rearrangement in an older male.
A 67-year-old man was admitted to the hospital with sore throat, dysphagia, and a lump in the right cervical region. Physical examination showed that the right palatine tonsil was enlarged and there was $2 \mathrm{~cm}$ of cervical lymphadenopathy unilaterally. After one week of antibiotic therapy, the lymphadenopathy still persisted. The patient underwent an excisional lymph node biopsy, which was consistent with LBCL of germinal center type, with a mainly follicular and focally diffuse pattern. The immunohistochemistry panel was positive for CD20 (clone L26; 